\title{
Identifying challenges and priorities for developing smart city initiatives and applications

\author{
Maja Čukušić ${ }^{1, *}$, Mario Jadrić ${ }^{1}$ ，Tea Mijač ${ }^{1}$ \\ ${ }^{1}$ Faculty of Economics, Business and Tourism, University of Split \\ Cvite Fiskovića 5, 21000 Split, Croatia \\ E-mail: 〈\{maja.cukusic, mario.jadric, tea.mijac\}@efst.hr $\rangle$
}

\begin{abstract}
The ubiquity of the technology and the availability of (open) data automatically collected in urban environments generate new opportunities, not only in tracking and managing public information services and resources, but also in the way we describe, implement and use these services. Although recent studies have proven that different smart city applications could improve some quality-of-life indicators by as much as 10-30 percent, at the same time it is reported that even the world cities that implement cutting-edge smart technologies are still at the beginning of their journey in a number of aspects. In an effort to identify and explore the challenges, the potential and the priorities for the implementation of smart city applications in a national/local context, a workshop followed by a research survey was conducted. To that end, a suitable research framework related to implementation of over 50 up-to-date smart city applications was adapted, extended and operationalized. The results of the study expose the strategic factors as the most challenging ones in the long-run in the national context of Croatia. In terms of local priorities for introducing smart city applications, the experts agreed on the most important and the least important smart city applications as well as on the potential to introduce these applications within 5 years. For the selection and prioritization of smart city applications in the given context, a proof-of-concept of a decision support tool intended for city managers is then proposed based on simulation modelling.
\end{abstract}

Keywords: smart city applications, smart city challenges, smart city priorities, simulation model

Received: January 28, 2019; accepted: March 15, 2019; available online: July 4, 2019

DOI: $10.17535 /$ crorr.2019.0011

\section{Introduction}

Consumerism and the widespread use of ICT are changing the way users today are consuming (information) services. Although the way in which the public sector communicates with users has changed considerably, there is a great deal of deviation in the quality of services between the private and public sectors [4]. From the public sector, users expect transparency and accessibility, or service that is at a level they get from the private sector. Unfortunately, this is often not the case $[1,32,10]$. An open debate about whether the concept of the quality of the provided services can be replicated from the private sector to the public sector is ongoing [17].

In respect to challenges to public administration and services, an important trend stems from the fact that the number of people inhabiting urban areas is constantly increasing [14]. By the end of 2020, urban population is expected to reach approximately $60 \%$ and by the end of 2050 up to $70 \%$ of the total population $[28,36,19]$. According to the United Nations Population Fund, 2008 was the year when more than $50 \%$ of all residents, 3.3 trillion, lived in urban areas [36]. In general, cities are faced with major changes and challenges arising from global shifts

${ }^{*}$ Corresponding author. 
in the environment, rapid urbanization, as well as older infrastructure. In that, the emerging technologies and advances in the internet development bring forth richer environments and support the ability to satisfy users' needs better [23], i.e. deliver specific information, services and products [2] while changing the way in which users/citizens communicate [41,39]. This is the era of informed citizens [1]. The two - an increase in the number of people living in cities and the constant progress of technology - resulted in the development and promotion of the concept of a smart city. To paraphrase only one of the many definitions of a smart city - it is important to note that it is a city that implements at least one initiative in one out of six areas: smart governance, smart people, smart living, smart mobility, smart economy and smart environment. Recent "Digital agenda for Europe" report promotes the use of more effective approaches supported by ICT for the provision of services and increasing quality of life thus pinpointing a specific goal of the public administration [11]. Back in 2012, the EC launched a Smart Cities and Communities initiative [31] contributing to the rise of the popularity of the concept/term. In essence, all definitions put focus on ICT as a driver and a prerequisite, while also emphasizing socio-economic, managerial and multi-stakeholder aspects [11,31, 37] since a smart city is a city with a high quality of life for all citizens, and is based on citizencentric approach [29]. Some relevant issues related to current state and employment of citizencentric approach in public administration and design of digital services are presented in section 2. Based on the identified issues and relevant worldwide evidence-based studies on smart city applications, we have prepared a research study in an effort to identify and explore the challenges and the potential for the implementation of the aforementioned smart city applications in a local context. The methodology, the results and conclusions of the study are presented in sections 3 , 4 , and 5 respectively.

\section{Issues related to developing citizen-centric smart city applications}

By popularizing the concept of smart cities, information services or systems in G2C (eGovernment) and C2G (eParticipation) environments are radically altered. Hereinafter, we view e-government as interconnected systems for management of public services that, based on ICT, should improve quality of services provided by governmental institutions to their stakeholders, increase their transparency, enable process improvements and achieve more efficient management [17]. In short, e-government should provide more adequate access to information and services in order to improve their quality and to increase citizens' participation with public administration [12]. Usually, five main categories of digital services are recognized with regards to whom the service is intended for [17]: G2B - government to businesses, G2C - government to citizens, G2E - government to its employees, G2G - government to government departments, and IEE - intra government.

It is important to note that research studies related to designing these types of services are still limited even though information systems today represent a strategic resource for public administration organizations as for any other organization. Implementing the digital service or just upgrading the existing one is often crucial to improving public services [4]. Every transformation of public administration must start by understanding the needs and priorities of citizens [10]. People should be central to such initiatives and that is why we highlight the importance of citizen-centric and citizen-driven services [3] again. Development of any digital service, regardless of type of public administration, is preceded by planning and analysis phase where user specifications and user data are collected usually through citizen journey mapping [32] that covers the entire experience of citizens who need the service [10] and present it visually, including the period before and after the specific experience with the service along with attitudes, feelings and needs of citizens [38]. The method gives a clear picture of why citizens use the services and thus leads to the optimization and allocation of required resources while it also enables the citizen-centric development. It is also in line with the concept of co- 
creation, an extremely important element of public institutions' strategies for becoming more user-oriented [13].

The continuous advancement of technology brings city managers into a position where, in line with citizens' demands and needs, they have to work on continuous development and (re)design of digital services with the aim to increase the use of such services. It is not a simple process since the lifecycle of digital services development should never end; a large number of applications are constantly being upgraded even without the knowledge of end users [34] and impact of new services on citizens is tested as their satisfaction may indeed have a decisive impact on the adoption and use of new services [40].

The user satisfaction phenomenon is particularly important in the public sector as it has different determinants [41] some of which are explored in the paper. Although it is clear that digital services for the public sector are expected to differ from those for the private sector, what they need to have in common is [1]:

- apart from providing a service and collecting user feedback, data generated in the process should be used for the purposes of reviewing the "wider picture" in terms of service usage

- following the analysis of the collected data, there has to be a loop to ensure transformation/evolution of the service, but also to inform policy modelling in relevant areas if applicable

The focus on citizen engagement and systematic development of e-government services (in line with what has been presented earlier) and the use of open data for creating services to citizens contributes to the quality of life in smart cities [7].

In addition to easier access to information as one of the benefits, digital services also reduce costs for the administration in the long run, and the development of smart city services is generally considered to be a cost-effective and efficient way to provide public services $[1,34]$. Consequently, the main interest during the service design has to be to meet citizens' needs and to reduce costs for the administration [20] to ensure that the development of digital services maximizes identified positive effects (positive impact on the business competitiveness, national economy outputs, environmental protection and negative impact on corruption [8]). However, this does not happen in the technology-first but in the citizens-first approaches [24, ?]. Even though ICT provides numerous possibilities for enabling more effective services, critics often emphasize that service providers do not prioritize and start with user-oriented approaches and end up with services that are not oriented towards the real needs of users [40,35]. In case of smart city services, often times citizen-oriented approach is not employed [3,34]. It is clear that there is a huge challenge for the public sector to identify and develop services in line with what citizens expect [13]. Also, a longitudinal study on the maturity of public digital services, demonstrated that it is much easier to achieve minimal level of maturity than to make a progress further on [8]. Even though investments in ICT are significant [30], the effect is actually not strictly correlated to the invested amount [21] but to quality of the service and an increase in user satisfaction [6]. The most expensive service is the one that is not used [23].

Taking all this into account, managers in the public administration have to make their decisions about the way to invest in ICT and develop new services; all for the benefits of the citizens analysing whether something could/should become a (smart) city application or not $[34,22]$. Once a city has decided to start its transformation towards becoming a smart city, it is important to evaluate its needs and innovation opportunities, set clear objectives, prioritize development efforts, and establish metrics [15] throughout the planning, management and operations phases. In addition to that, it is very important to maintain strategic point of view $[25,9]$ and engage the citizens in the process. Theory suggests that it is best to begin with areas that are urgent or have pressing issues. Authors suggest three main determinants that together comprise an essential tool for advancing the vision for smart city design initiatives [26]: 
i) citizen engagement, ii) governance and iii) ICT infrastructure. One of the good examples initiative is Barcelona that developed a strategic plan for becoming a smart city already in 1990s [18]. The approaches vary from the top-down and the bottom-up approaches based on the context of the city, but also on the knowledge and creativity of the citizens [9].

From the evidence presented here, it is clear that there are a number of issues related to use of citizen-centric approaches and the design of digital services especially in the context of nowmodern smart cities. Managers and planners of smart city initiatives (in developing strategies and policies in particular) should be aware both of the challenges and the potential for the implementation of the smart city services/applications in their local contexts. That is why this paper in its second part in particular focuses on the following questions: i) which of the presented challenges are considered the most relevant ones, ii) which smart city services/applications should get the highest priority and iii) what are the possibilities of using a simulation model to prioritize the services/applications for future implementation; all in an effort to put forward and validate a useful model and accompanying tool for smart city decision makers.

\section{Research methodology and the survey structure}

To provide answers to the listed questions, a dedicated workshop and, as a follow-up, a research survey were organized in July 2018 in an effort to identify specific challenges and priorities for developing smart city initiatives and applications. The research instrument consisted of two parts, first one related to challenges (1 page) and the second one to potentials and priorities (5 pages) in developing smart city initiatives and applications:

- Part 1: Challenges for developing smart city initiatives with a list of 17 different challenges to be rated i) on a 5-point Likert scale in terms of their relevance and ii) the timeframe when the specific challenges are/become relevant, i.e. short-term, medium-term, or longterm.

- Part 2: Potentials and priorities for developing smart city initiatives with a categorized list of 59 smart city applications where i) the potential for introducing the application within 5 years was rated as Yes or No, and ii) the priority for the city was rated on a 5-point Likert scale.

The list with 17 different challenges (part 1) in developing smart city initiatives and applications (all presented in Table 1 in the next chapter) was based on four studies [37, 21, 15, ?]. The list and the descriptions of the smart city applications (part 2) were entirely taken from the recent research study [7] that looked at dozens of smart applications that will be relevant for cities through 2025 and gathered evidence from 50 cities from around the globe to assess how smart city applications could affect various quality-of-life dimensions: safety, time and convenience, health, environmental quality, social connectedness and civic participation, jobs, and the cost of living. Having this in mind, we wanted to assess the potential and priorities for the implementation of these applications in Croatia within the five-year period and the priorities for one specific location - City of Split. This study was conducted within the framework of a project related to user-oriented process (re)design and information systems modelling in smart cities. One of the stakeholders invested in the project is City of Split and all the survey respondents are from Split or its urban agglomeration.

The list with the appropriate (original) descriptions of applications is too long, thus we enclose only a categorized catalogue of the applications (total of 59):

- Engagement and community: digital citizen services, local civic engagement applications, local connection platforms 
- Economic development and housing: digital business licensing and permitting, digital business tax filing, digital land-use and building permitting, local e-career centres, Online retraining programs, open cadastral database, peer-to-peer accommodation platforms, personalized education

- Energy: building automation systems, distribution automation systems, dynamic electricity pricing, home energy automation systems, home energy consumption tracking, smart streetlights

- Waste: digital tracking and payment for waste disposal, waste collection route optimization

- Water: leakage detection and control, smart irrigation, water consumption tracking, water quality monitoring

- Mobility: autonomous vehicles, bike sharing, car sharing, congestion pricing, demandbased microtransit, digital public transit payment, e-hailing (private and pooled), integrated multimodal information, intelligent traffic signals, parcel load pooling, predictive maintenance of transportation infrastructure, real-time public transit information, realtime road navigation, smart parcel lockers, smart parking

- Security: body-worn cameras, crowd management, data-driven building inspections, disaster early-warning systems, emergency response optimization, gunshot detection, home security systems, personal alert applications, predictive policing, real-time crime mapping, smart surveillance

- Healthcare: data-based public health interventions for maternal and child health, databased public health interventions for sanitation and hygiene, first aid alerts, infectious disease surveillance, integrated patient flow management systems, lifestyle wearables, realtime air quality information, remote patient monitoring, telemedicine.

The workshop attendees were experts $(N=17)$ who were asked to assess the challenges, the potential and priorities for introducing the innovative smart city applications (under already listed categories) in the city within the next five-year period. As a follow up, survey respondents $(N=60)$ with a keen interest in smart cities (citizens of the local community that are at the same time professionals and have a HE degree in the ICT field) helped us to identify the most important short-, medium-, and long-term challenges (e.g. community engagement, digital divide and so on) for smart city initiatives in Croatia. In other words, the experts (people researching and working in smart city domain) completed both parts of the survey, while the other respondents completed only the first part of the survey. The results collected from the experts during the workshop were planned to be used to propose a simulation model to be used by decision makers before the implementation of any smart city initiative begins, specifically in the planning phase. Therefore, it was acknowledged that participants without the strong knowledge about smart cities could not be involved in this part of the study.

\section{Research results and discussion}

As the research study approached two different types of participants and consisted of two distinctive parts, the results are presented in two separate sections - data on smart city implementation challenges and priorities respectively. 


\subsection{Analysing smart city challenges data}

For all 17 listed challenges for smart city initiatives in Croatia, the participants were asked to select its relevancy. The scale was set from 1 - not relevant to 5 - most relevant. Apart from the relevancy, participants were asked to determine whether listed challenges should be considered as short, medium, or long-term challenges. Statistical method used to describe variability among observed, correlated variables was exploratory factor analysis. The sample was tested using Keiser-Meyer-Olkin test and Bartlett's test. Adequacy of the sample is appropriate $(K M O=0.813)$ and Bartlett's test is statistically significant $(p<0.05)$. The rotated component matrix (in Table 1) demonstrates the three groups representing the types of challenges. The factor extraction method used was Principal Components Analysis. The number of factors was determined using the Kaiser-Guttman's criterion. The three factors account for $65.84 \%$ of the total variance. Three specific challenges (CH17, CH16 and CH13) were excluded from further analysis due to high cross loading on more than one factor. The eigenvalue results of the PCA for the three groups are 8.001, 1.930 and 1.261 respectively and Cronbach's alpha scores are $0.847,0.874$ and 0.780 respectively.

\begin{tabular}{|l|ccc|}
\hline \multicolumn{1}{|c|}{ challenge } & F1 & F2 & F3 \\
\hline CH11: Establishing partnerships & 0.787 & & \\
CH10: Financial aspects & 0.698 & & \\
CH07: Open data access & 0.690 & & \\
CH04: Community engagement & 0.683 & & \\
CH17: Collaboration between City Departments/Enterprises & 0.674 & 0.507 & \\
CH09: Policy changes & 0.667 & & \\
CH16: Understanding users' needs & 0.615 & 0.605 & \\
CH13: Data revolution & 0.515 & & 0.511 \\
CH03: Combination of different technologies & 0.515 & & \\
CH02: Leadership and vision & & 0.861 & \\
CH01: Decision makers (qualification and reediness) & & 0.861 & \\
CH14: Design of smart city initiatives & & 0.768 & \\
CH15: Implementation of smart city initiatives & & 0.694 & \\
CH05: Standards & & & 0.805 \\
CH08: Regulations on data protection and privacy & & & 0.783 \\
CH12: Digital divide & & & 0.704 \\
CH06: Interoperability & & & 0.548 \\
\hline
\end{tabular}

Table 1: Rotated component matrix

The analysis leaves us with three factors (F1, F2 and F3) and 14 items. Qualitative analysis and relevant studies that the list of challenges is based upon enables us to interpret and title the factors as follows: F1 "Operational challenges", F2 "Strategic challenges" and F3 "External challenges". Descriptive statistics for each of these in presented in Table 2.

\begin{tabular}{|l|ccccc|}
\hline \multicolumn{1}{|c|}{ factors } & $\mathrm{N}$ & $\min$ & $\max$ & mean & std. dev. \\
\hline F1: Operational challenges & 59 & 2.33 & 5.00 & 4.10 & 0.63721 \\
F2: Strategic challenges & 60 & 2.00 & 5.00 & 4.21 & 0.73382 \\
F3: External challenges & 60 & 2.50 & 5.00 & 3.88 & 0.68189 \\
\hline
\end{tabular}

Table 2: Descriptive statistics for three factors

In terms of the timeframes when the challenges are (or would become) relevant, the participants agree that this is not in the short term as illustrated in Figure 1. Overall, only $13 \%$ are categorized as short-term and, almost equally, $42 \%$ as medium-term and $45 \%$ as long-term 
challenges. As mentioned earlier, a study [7] found that even the most cutting-edge smart cities on the planet are still at the beginning of their journey. In line and acknowledging this, the participants agree and assess the challenges for the implementation of smart city applications in Croatia as not entirely relevant for the time being.

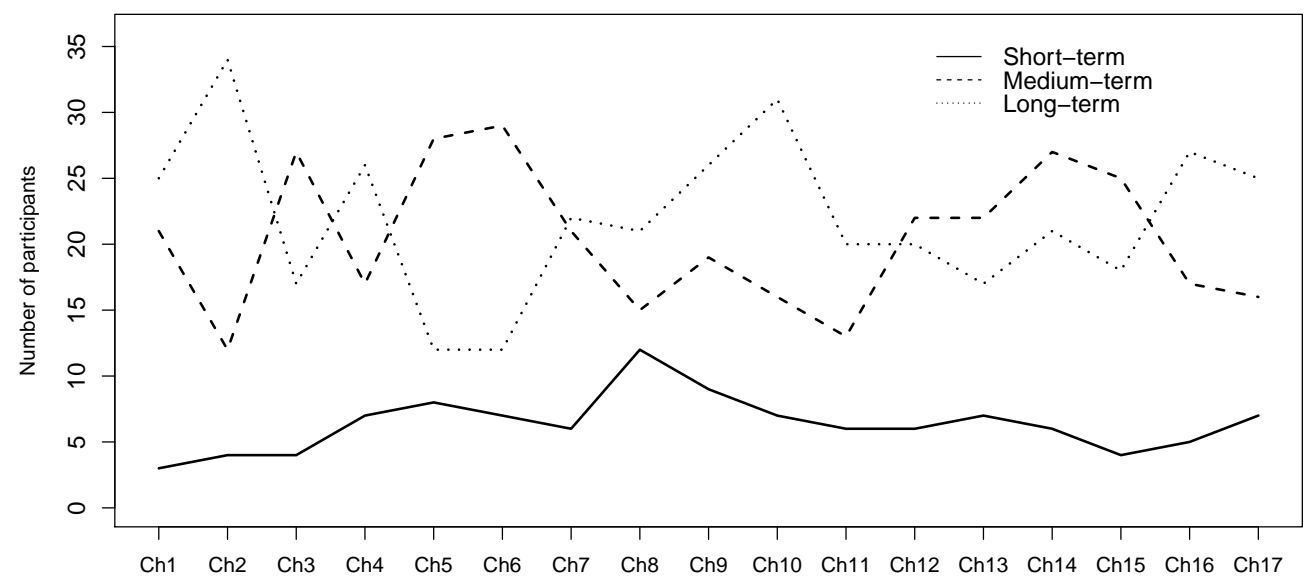

Figure 1: Time frame when the specific challenges are/become relevant

\subsection{Analysing smart city priorities data}

For the second part, as already mentioned, only experts were invited to assess categorized catalogue of the applications under different categories (1 - Engagement and community, 2 Economic development and housing, 3 - Energy, 4 - Waste, 5 - Water, 6 - Mobility, 7 - Security and 8 - Healthcare). They were asked to assess the potential to implement these applications within the next five-year period and to determine the priority for introducing specific smart city applications in the City of Split. The scale was set from 1 - not a priority to 5 - extremely high priority.

We analysed the data for the whole dataset but present hereinafter only a subset (for the 11 applications under categories 1 - Engagement and community and 2 - Economic development and housing). There are several reasons for this decision. First of all, the number of applications is quite large (59) and would require space to present all the data and time to develop a simulation model that is five times bigger than the one presented here. Secondly, due to a small number of experts (17) who participated in this workshop, all distributions were not statically significant. Finally, the purpose of this part of the research was to use the data to build only a proof-of-concept simulation model (presented in section 4.3) that could be, among other purposes, used in the future by city managers for planning and observing the dynamics of the specific initiatives, taking in the consideration custom priorities set by the users themselves. The mean priorities and other descriptive statistics for the first part of the list - the 11 smart city applications are presented in Table 3 and were used for building the simulation model.

To offer an insight into the whole dataset, we will present a short overview of the mean scores: out of all 59 applications, in terms of priorities the experts agree that water quality monitoring (4.647) and smart parking (4.471) are the most important priorities for City of Split. This is in line with the common issues of this coastal city crowded with tourists and frequent water quality issues that follow heavy rain periods. The three least important priorities as identified by experts are local connections platform (2.765), autonomous vehicles (2.765) and congestion pricing (2.529). In terms of the potential, all find that Smart parking, real-time 
public transit information, digital public transit payment, local connection platforms and local civic engagement applications could be implemented, while applications such as autonomous vehicles and distribution automation systems could not be implemented within the next five years in the city. This is also in line with the given context and the current research in the smart mobility segment, since one of the first services offered to citizens and marketed as a smart city solution in Split was smart parking.

\begin{tabular}{|l|ccccclc|}
\hline priority & $\mathrm{N}$ & $\min$ & $\max$ & mean & std. dev. & \multicolumn{1}{c|}{ distribution } & potential \\
\hline CAT1-01 & 15 & 3.0 & 5.0 & 4.133 & 0.9155 & $2.5+3 \times \operatorname{BETA}(0.906,0.758)$ & $87.5 \%$ \\
CAT1-02 & 17 & 1.0 & 5.0 & 3.588 & 0.9393 & NORM $(3.59,0.911)$ & $100.0 \%$ \\
CAT1-03 & 17 & 1.0 & 5.0 & 2.765 & 1.2515 & TRIA $(0.5,3,5.5)$ & $100.0 \%$ \\
CAT2-04 & 17 & 1.0 & 5.0 & 4.412 & 1.0641 & $0.5+5 \times \operatorname{BETA}(2.16,0.601)$ & $88.2 \%$ \\
CAT2-05 & 16 & 2.0 & 5.0 & 4.000 & 0.8944 & $1.5+4 \times \operatorname{BETA}(2.74,1.69)$ & $87.5 \%$ \\
CAT2-06 & 17 & 2.0 & 5.0 & 4.176 & 0.9510 & $1.5+4 \times \operatorname{BETA}(1.95,0.965)$ & $64.7 \%$ \\
CAT2-07 & 17 & 2.0 & 5.0 & 3.706 & 0.9852 & $1.5+\operatorname{LOGN}(2.24,1.2)$ & $82.4 \%$ \\
CAT2-08 & 16 & 2.0 & 5.0 & 3.625 & 0.9574 & $1.5+4 \times \operatorname{BETA}(2.04,1.81)$ & $93.8 \%$ \\
CAT2-09 & 16 & 2.0 & 5.0 & 4.125 & 1.2042 & $1.5+4 \times \operatorname{BETA}(0.977,0.512)$ & $50.0 \%$ \\
CAT2-10 & 17 & 1.0 & 5.0 & 3.235 & 1.0914 & NORM $(3.24,1.06)$ & $94.1 \%$ \\
CAT2-11 & 17 & 1.0 & 5.0 & 3.059 & 1.0290 & $0.5+5 \times \operatorname{BETA}(2.86,2.73)$ & $76.5 \%$ \\
\hline
\end{tabular}

Table 3: Descriptive statistics of priorities and potentials for developing smart city initiatives under categories 01 and 02

\subsection{Developing a decision support tool for (smart) city managers}

The simulation model is developed as a decision support tool proof-of-concept in order to demonstrate its feasibility and practical potential in the smart city planning and development processes (Figure 2). The tool used for building a simulation model is Arena, simulation software by Rockwell Automation (USA). Among its other features, Arena enables business process simulations. The tool can also be used for performance estimates based on key indicator data, such as cost, cycle time, etc., as well as for identifying problems in business processes and planning and developing [5].

For all the above mentioned reasons and for the time being, the created model contains only the applications from the two categories. Acknowledging all the processes behind planning and developing smart city initiatives, the model represents a rather simplified version of the decision making process but also including public tender preparation and other administrative procedures. Specifically, having a large portfolio of all possible/available smart city applications, and based on the internally- and/or externally-set priorities (however, including citizens' opinions) and (expert) assessment about whether it is possible or not to implement the application within a five-year timeframe, a city manager can experiment to select the optimal set of applications handled by one office/department. As the main issues related to strategic and planning segments in the City of Split, competences (qualification and reediness), design and preparation processes are identified as the most challenging ones. Using the model and its extended version planned to be built in the future, it is possible to experiment and increase department resources for better planning and organisation.

To demonstrate this, as a simulation setting of an experiment a number of replications was set to 100 for the five-year period. The applications were the entities that flow through the process. Regarding the inter-arrival time, random exponential distribution with 10-days mean time and maximum arrival is 1 entity. The same setup was configured for all applications within all categories. There are two Assign modules in the model. In the first one, all applications are assigned Entity type in order to name, differentiate and analyse the applications within the categories (for example Digital citizen services). The second Assign module adds a priority 
attribute based on distribution data presented in Table 3. For example, for Digital citizen services the attribute distribution is set to $2.5+3 \times \operatorname{BETA}(0.906,0.758)$.

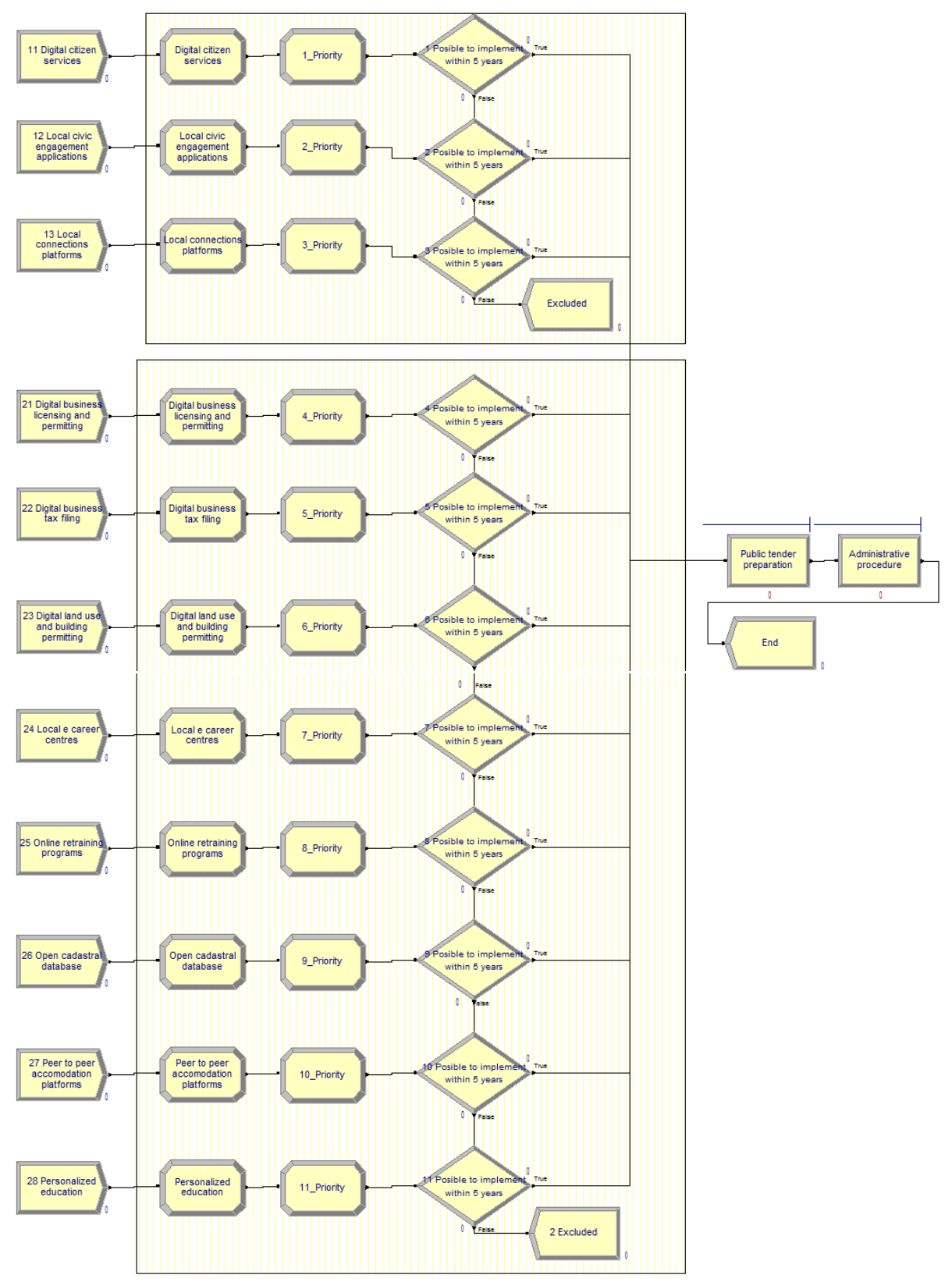

Figure 2: Proof-of-concept simulation model for categories 01 and 02 of smart city applications

Using the Decide module, the process branches based on the identified potential for introducing the application within 5 years presented in Table 3. In terms of the experiment setup, two resources are allocated, one employee for public tender preparation and another one for resolving administrative procedures. As an action Seize Delay Release was configured to indicate that employees will be allocated followed by a process delay typical for queuing processes. The time distribution for Public tender preparation is triangular with a minimum of 1 day, a 
maximum of 15 days, and a most likely value of 10 days, while the distribution for Administrative procedures is triangular with a minimum of 30 days, a maximum of 90 days, and a most likely value of 60 days. A triangular random variable is used when the underlying distribution is unknown, but it is reasonable to assume that the timeframe ranges from a minimal value to some maximal value, with the most likely value being somewhere in between. This is an input, we agreed upon consultation with an expert who is knowledgeable on public tendering processes.

Table 4 presents the results of the simulation experiment where total process time is expressed in number of days for the same 11 smart city applications. The time represents the number of days until the implementation of the specific application starts ranging from 63.83 to 463.87 days on average. The results of the simulation experiment are consistent with experts' perceptions of priorities and the potentials since for example, the Local connections platform (from category 01) had the lowest priority set (mean 2.765) and consequently has the highest total time as a result of the simulation, requiring 463.87 days on average before starting its design and implementation.

\begin{tabular}{|l|ccc|}
\hline \multicolumn{1}{|c|}{ total process time (number of days) } & average & min avg. & max avg. \\
\hline CAT1-02: Local civic engagement applications & 332.97 & 51.90 & 674.10 \\
CAT1-03: Local connections platform & 463.87 & 202.62 & 705.10 \\
CAT1-01: Digital citizen services & 63.83 & 0.00 & 100.99 \\
CAT2-04: Digital business licensing and permitting & 229.06 & 0.00 & 631.70 \\
CAT2-05: Digital business tax filling & 292.90 & 0.00 & 601.66 \\
CAT2-06: Digital land use and building permitting & 205.44 & 0.00 & 610.57 \\
CAT2-07: Local e-career centers & 268.24 & 0.00 & 652.65 \\
CAT2-08: Online retraining programs & 331.50 & 0.00 & 620.26 \\
CAT2-09: Open cadastral database & 157.49 & 0.00 & 665.18 \\
CAT2-10: Peer to peer accommodation platforms & 345.73 & 0.00 & 688.48 \\
CAT2-11: Personalized education & 349.19 & 0.00 & 712.79 \\
\hline
\end{tabular}

Table 4: Results of a simulation experiment in Arena

\section{Conclusion}

One of the aims of the presented research was to determine the relevancy of previously identified (international) challenges for the implementation of future smart city initiatives in a national and local context. Once appropriately identified, these challenges could be tracked, measured and properly tackled with as a part of several smart city initiatives that have already started (e.g. Split Smart City) or are about the start (e.g. concept SMART by Ministry of Regional Development and EU Funds as of early 2019). To emphasize, the findings from the first part of the study confirm that all participants, regardless of their stakeholder status, choose the second factor - Strategic challenges as the most relevant in our national context. This is inline and consistent with the presented theoretical background, since many international authors agree that the strategic point of view should be the starting point for implementing smart city initiatives, highlighting the importance of evaluating innovation opportunities, setting clear objectives and prioritizing efforts. In order to tackle identified smart city challenges, there is a real need to get the wider perspective and have a clear vision. Furthermore, with regards to the second factor, Operational challenges refer to issues regarding the specific (inter)national context which, among other, supports the need to meet the expected levels of citizens' satisfaction and implement the initiatives that are in line with citizens' needs and priorities as is argued in the paper as well. As for the External challenges, these imply external forces, ones that city planners alone cannot have a direct impact on but that have to be taken into account when planning and designing the initiatives. 
To further explore the context and identify the priorities for internationally-implemented smart city initiatives with citizens and experts, a preliminary study yielded valuable insights into our understanding of smart city applications and concepts in a local context - the City of Split. Realistically, the participants identified the areas (Water and Mobility) where the smart city applications could make an actual difference in the time frame of the next five years to tackle authentic city crises. By using the identified priorities and potentials (based on the existing infrastructure, technological maturity and other factors), the second part of research encompassed the presentation of possible directions and of the potential for using simulation modelling as one of the approaches for planning and optimizing the implementation of plethora of smart city applications. Experts' estimations were used to build only a proof-of-concept i.e. a part of a simulation model to confirm that the use of simulations could make the process of deciding about which applications to implement and when a lot easier and that it could improve the efficiency of a designated city department. It could be argued that the extended and a more user-friendly version of the model would be feasible, useful and that it would have the practical potential. The same approach was used in another study [43] by authors of the paper to investigate the implications of smart systems implementation, specifically in the context of smart technologies in airport operations as a part of ongoing smart mobility initiatives and solutions.

However, the presented research has several limitations that would be taken into account and dealt with in further research. For example, further research should be expanded to other cities facing the identified challenges nationally-wide, since it was explored for only one city in Croatia - Split. Local and national context should have many similarities, but should differentiate significantly to smart city challenges that cities in e.g. India face. Another limitation is a small number of experts resulting in skewed distributions of the results. Furthermore, it would be worthwhile to extend the proposed simulation model, since this proposed proof of concept did not include variable such as resource costs, which could provide a valuable and, by all means, a better perspective for decision makers. Also, another possibility of enhancing the model is by introducing the costs of introducing new applications (both including the software development fees and implementation fees) to get better insights and estimates using the simulation model. To conclude, even though it can be argued that this research included a small number of participants, it provided significant results. The results of this research could be important to all relevant stakeholders of smart city initiatives, since the number of possible applications is growing each day. The studies show that it is much easier to achieve a minimal level of maturity than to make a progress further on and with this in mind the city managers should start listening to citizens and start designing.

\section{Acknowledgements}

This work has been supported by the Croatian Science Foundation under the project UIP-201705-7625 "User-oriented process (re)design and information systems modelling - a case of smart city services".

\section{References}

[1] Agrawal, V., Mittal, M. and Rastogi, L. (2003), ENABLING e-GOVERNANCE. Delhi Bussines Review, 4(1), 1-14. http://www .delhibusinessreview.org/v4n1.htm

[2] Alawneh, A., Al-Refai, H. and Batiha, K. (2013). Measuring user satisfaction from e-Government services: Lessons from Jordan. Government Information Quarterly, 30(3), 277-288. doi: 10.1016/j.giq.2013.03.001

[3] Albino, V., Berardi, U. and Dangelico, R. M. (2015). Smart Cities: Definitions, Dimensions, Performance, and Initiatives. Journal of Urban Technology, 22(1), 1723-1738. doi: 10.1080/10630732.2014.942092 
[4] Baig, A., Dua, A. and Riefberg, V. (2014). Putting Citizens First: How to improve citizens' experience and satisfaction with government services. https://mck.co/2T3LSFz [Accessed 15/03/2019].

[5] Bakici, T., Almirall, E. and Wareham, J. (2013). A Smart City Initiative: the Case of Barcelona. Journal of the Knowledge Economy, 4(2), 35-148. doi: 10.1007/s13132-012-0084-9

[6] Brown, A., Fishenden, J. and Thompson, M. (2014). Digitizing Government. New York: Palgrave Macmillan.

[7] Chui, M., Lund, S., Madgavkar, A., Mischke, J. and Ramaswamy, S. (2018). Smart Cities: Digital Solutions for a More Livable Future. Mckinsey Global Institute Publication. https://www.mckinsey.com/ /media/mckinsey/industries/capital $\% 20$ projects $\% 20$ and $\%$ 20 infrastructure/our $\% 20$ insights/smart $\% 20$ cities $\% 20$ digital $\% 20$ solutions $\% 20$ for $\% 20$ a $\%$ 20 more $\% 201$ ivable\%20future/mgi-smart-cities-full-report.ashx

[8] Das, A., Singh, H. and Joseph, D. (2017). A longitudinal study of e-government maturity. Information and Management, 54(4), 415-426.

[9] Degbelo, A., Granell, C., Trilles, S., Bhattacharya, D., Casteleyn, S. and Kray, C. (2016). Opening up Smart Cities: Citizen-Centric Challenges and Opportunities from GIScience. ISPRS International Journal of Geo-Information, 5(2), 16. doi: 10.3390/ijgi5020016

[10] Dudley, E., Lin D. Y., Mancini, M. and Ng, J. (2015). Implementing a citizen-centric approach to delivering government services. https://www.mckinsey.com/industries/public-sector/ our-insights [Accessed 15/03/2019].

[11] European Commision. (2014). Digital agenda for Europe. doi: 10.2775/41229

[12] Fang, Z. (2002). E-Government in Digital Era: Concept, Practice, and Development. International Journal of the Computer, the Internet and Management, 10(2), 1-22. http://www.ijcim.th.org/ past_editions/2002V10N2/v10n2.htm

[13] Gouillart, F. and Hallett, T. (2015). Co-Creation in Government. Stanford Social Innovation Review, 41--47. https://ssir.org/articles/entry/co_creation_in_government

[14] Hajduk, S. (2016). The concept of a smart city in urban management. Business, Management and Education, 14(1), 34-39. doi: 10.3846/bme.2016.319

[15] Islam, M. M. and Ehsan, M. (2015). Understanding E-Governance: A Theoretical Approach, 18111823. In Public Affairs and Administration: Concepts, Methodologies, Tools, and Applications, Information Resources Management Association (USA). doi: 10.4018/978-1-4666-8358-7.ch093

[16] Jadrić, M., Čukušić, M. and Bralić, A. (2014). Comparison of discrete event simulation tools in an academic environment. Croatian Operational Research Review, 5(2), 203-219. doi: 10.17535 /crorr. 2014.0008

[17] Janita. M. S. and Miranda, F. J. (2018). Quality in e-Government services: A proposal of dimensions from the perspective of public sector employees. Telematics and Informatics, 35(2), 457-469. doi: 10.1016/j.tele.2018.01.004

[18] Kogan, N. and Lee, K. J. (2014). Exploratory Research on the Success Factors and Challenges of Smart City Projects. Asia Pacific Journal of Information Systems , 24(2), 141-189. doi: 10.14329/apjis.2014.24.2.141

[19] Lierow, M. (2012). B2CITY: The next wave of urban logistics. https://www.oliverwyman.com [Accessed 15/03/2019].

[20] Magoutas, B. and Mentzas, G. (2010). SALT: A semantic adaptive framework for monitoring citizen satisfaction from e-government services. Expert Systems with Applications, 37(6), 42924300. doi: 10.1016/j.eswa.2009.11.071

[21] Maguire, S. and Redman, T. (2006). The role of human resource management in information systems development. Management Decision, 45(2), 252-264. doi: 10.1108/00251740710727278

[22] Morgeson, F. V., VanAmburg, D. and Mithas, S. (2011). Misplaced Trust? Exploring the Structure of the E-Government-Citizen Trust Relationship. Journal of Public Administration Research and Theory, 21(2), 257-283. doi: 10.1093/jopart/muq006

[23] Mun, Y. Y. and Yujong, H. (2003). Predicting the use of web-based information systems: selfefficacy, enjoyment, learning goal orientation, and the technology acceptance model. International Journal of Human-Computer Studies, 59(4), 431-449. doi: 10.1016/S1071-5819(03)00114-9

[24] Nam, T. (2014). Determining the type of e-government use. Government Information Quarterly, 31(2), 211-220. doi: 10.1016/j.giq.2013.09.006

[25] Naphade, M., Banavar, G., Harrison, C., Paraszczak, J. and Morris, R. (2011). Smarter Cities 
Identifying challenges and priorities for developing smart city initiatives and applications

and Their Innovation Challenges. Computer, 44(6), 32-39. doi: 10.1109/mc.2011.187

[26] Paskaleva, K. A. (2009). Enabling the smart city: the progress of city e-governance in Europe. International Journal of Innovation and Regional Development, 1(4), 405. doi: 10.1504/ijird.2009.022730

[27] Pavlić, D., Jadrić, M. and Čukušić, M. (2018). Discrete simulation modeling of intelligent passenger boarding. Proceedings of the 41st International Convention on Information and Communication Technology, Electronics and Microelectronics (MIPRO). doi: 10.23919/mipro.2018.8400230

[28] Popescu, R. (2011). Study regarding the ways of measuring cities competitiveness. Econ Ser Manag, 14(2), 288-303.

[29] SMACC. (2015). Smart City Coaching Multi-stakeholder training concepts for the city of the future. Graz. http://www.smacc-project.eu [Accessed 10/01/2019].

[30] SmartCities. (2013). Customer Journey Mapping. https://bit.ly/2TQaZA2 [Accessed 15/03/2019].

[31] Snow C. C., Håkonsson, D. D. and Obel, B. (2016). A Smart City is a Collaborative Community: Lessons from Smart Aarhus. California Management Review doi: 10.1177/0008125616683954

[32] Spaven, F. (2016). How A Customer Journey Map Builds Better Software. https://raygun.com/ blog/customer-journey-map [Accessed 15/03/2019].

[33] Tan, C. W., Benbasat, I. and Cenfetelli, R. T. (2013). IT-mediated customer service content and delivery in electronic governments: an empirical investigation of the ancedents of service quality. MIS Quarterly, 37(1), 77-109. doi: 10.25300/misq/2013/37.1.04

[34] Tomitsch, M. (2018). Making Cities Smarter (Designing Interactive Urban Applications). Berlin: JOVIS Publisher.

[35] Thompson, D. V., Rust, R. T. and Rhoda, J. (2005). The business value of e-government for small firms. International Journal of Service Industry Management, 16(4), 385-407. doi: $10.1108 / 09564230510614022$

[36] UN (2014). World's population increasingly urban with more than half living in urban areas. https: //www.un.org

[37] Van den Bergh, J. and Viaene, S. (2016). Unveiling smart city implementation challenges: The case of Ghent. Information Polity, 21(1), 5-19. doi: 10.3233/ip-150370

[38] Vatsyayan, U. (2017). Importance of 'citizen journey mapping' for effective government service delivery. https://www.linkedin.com/pulse/ importance-citizen-journey-mapping-effective-service-utsav-vatsyayan [Accessed $15 / 03 / 2019]$.

[39] Venkatesh, V., Chan, F. K. Y. and Thong, J. Y. L. (2012). Designing e-government services: Key service attributes and citizens' preference structures. Journal of Operations Management, 30(1-2), 116-133. doi: 10.1016/j.jom.2011.10.001

[40] Verdegem, P. and Verleye, G. (2009). User-centered E-Government in practice: A comprehensive model for measuring user satisfaction. Government Information Quarterly, 26(3), 487-497. doi: 10.1016/j.giq.2009.03.005

[41] Wirtz, B. W. and Kurtz, O. T. (2016). Local e-government and user satisfaction with city portals - the citizens' service preference perspective. International Review on Public and Nonprofit Marketing, 13(3), 265-287. doi: 10.1007/s12208-015-0149-0 